\title{
10 health stories that mattered Apr. 14-17
}

- Ontario's Information and Privacy Commissioner Ann Cavoukian called for police to cease routine disclosure of information about attempted suicides in the province to United States border officials. The recommendation is the result of an investigation into stories of Ontarians being denied entry to the US, apparently on the basis of their mental health history.

- The Public Health Agency of Canada released updated guidelines for prevention of malaria. The new guidance recommends insect repellents containing 20\%-30\% DEET or $20 \%$ icaridin as a first line of defence against mosquitos; sets new thresholds for use of malaria chemoprophylaxis based on travel duration; and provides more information for special groups, including children, migrants, pregnant women and travellers with comorbidities.

- Ontario's governing Liberals promised limited coverage of fertility services. The province will cover one cycle of in vitro fertilization for all forms of infertility starting early next year. However, the plan won't cover the costs of drugs and other services associated with the treatment, which can run to thousands of dollars.

- Ontario updated immunization requirements for school children to include new mandatory immunizations and dose requirements. All students attending primary or secondary schools this fall, unless exempted, will need proof of immunization against meningococcal disease, whooping cough and chicken pox. This is in addition to updated dose requirements for tetanus, diphtheria, polio and mumps immunizations.

- A study published in CMAJ revealed that pharmacist care improves blood pressure and cholesterol control in stroke patients who had experienced a minor stroke. Active patient management by pharmacists with prescribing authority was shown to substantially improve risk factor control at six months in these patients.

- An investigation into prescribing practices in federal prisons was launched by Correctional Investigator of Canada Howard Sapers, after reports of widespread overprescribing to female inmates. More than $60 \%$ of female inmates are receiving psychiatric medication, according to data collected by Sapers in 2013.

- A group representing abortion providers in Canada and the United States called on New Brunswick to relax restrictions on the procedure after the hospital that provides nearly all publicly funded abortions in the province announced it will suspend the service. The National Abortion Federation asked that the province cover abortions performed at a private clinic in Fredericton so that women don't have to travel to Nova Scotia or Quebec at the taxpayer's expense.

- Information about conditions at personal care homes in Saskatchewan became available online, after recent changes to legislation enabled the province to share inspection reports with the public.

- British Columbia's privacy watchdog urged tougher rules for background checks, reporting that police disclose too much mental health information to employers. Government and police boards should immediately stop providing mental health information as part of these checks, said Information and Privacy Commissioner Elizabeth Denham.

- Scientists slammed a new Royal Society of Canada review of safety standards for radiofrequency devices for failing to weigh recent evidence of cancer risks. Two experts invited to peer review the report also expressed grave concerns over the authors' conflicts of interest and lack of expertise. — Lauren Vogel, CMAJ

CMAJ 2014. DOI:10.1503/cmaj.109-4786 